\title{
AC 2007-2731: THE ACADEMY OF COURAGEOUS MINORITY ENGINEERS: A MODEL FOR SUPPORTING MINORITY GRADUATE STUDENTS IN THE COMPLETION OF SCIENCE AND ENGINEERING DEGREES
}

\author{
Eric Brittain, Massachusetts Institute of Technology \\ Eric Brittain is a $\mathrm{PhD}$ candidate in the Electrical Engineering and Computer Science Dept. at \\ MIT. He received his BS from Clark Atlanta Univ, and his MS from MIT EECS. His research lies \\ in Brain and Computer Interaction.
}

\section{Reginald Bryant, Massachusetts Institute of Technology}

Reginald Bryant is a PhD candidate in the Electrical Engineering and Computer Science Dept. at MIT. He received his BS from Morgan State University, and his MS from MIT EECS. His research efforts are currently focused on micromachining integrated NanoElectroMechanical (NEM) High-Index-Contrast (HIC) thin film structures.

\section{Lincoln Chandler, Massachusetts Institute of Technology}

Lincoln Chandler is a PhD candidate affiliated with the MIT Operations Research Center. His current research addresses the characterization and evolution of differences in academic performance among ethnic groups, commonly referred to "achievement gaps." He holds a BS in Computer and Information Sciences from Florida A\&M University and a SM degree in Operations Research from MIT.

\section{Robbin Chapman, Massachusetts Institute of Technology}

Dr. Robbin Chapman received her Ph.D. in Electrical Engineering and Computer Science from Massachusetts Institute of Technology's Electrical Engineering and Computer Science department. Her research explores computational tools and practices for promoting critical reflection within design-based learning activities. Her theoretical framework, Cooperative Constructionism, establishes a design-based approach to critical reflection with applicable computational tools and teaching pedagogy. Her publications include chapters in Social Capital and Information Technology and the forthcoming book, Communities of Practice: Creating Learning Environments for Educators. Dr. Chapman has served as Assistant Program Director for NASA's Space Life Sciences Training Program at Kennedy Space Center and was a member of the Life Sciences Support facility flight hardware team at Cape Canaveral.

\section{Shaundra Daily, Massachusetts Institute of Technology}

Shaundra Bryant Daily is a doctoral candidate at the Massachusetts Institute of Technology Media Laboratory working in the Affective Computing Group. She holds a Bachelor (2001) and Master (2003) of Science in Electrical Engineering from the Florida Agricultural and Mechanical-Florida State University College of Engineering. She also completed a Master of Science (2005) degree at the Media Laboratory where she designed, built, and evaluated interfaces to support affective development through digital storytelling enhanced with commonsense reasoning technology. Her main research interests include the design of computational tools to enable reflection on emotions, attitudes, beliefs, and values.

\section{Mark Hampton, Massachusetts Institute of Technology}

Mark Hampton is a $\mathrm{PhD}$ candidate in the MIT Department of Electrical Engineering and Computer Science. His research interests include parallel computer architectures and energy-efficient architectural techniques. He has BS degrees in computer and systems engineering as well as computer science from Rensselaer Polytechnic Institute, and an SM degree in electrical engineering and computer science from MIT. 
Ishara Mills-Henry, Massachusetts Institute of Technology

Ishara Mills is a postdoctoral fellow in the Biology Dept. at MIT. She recently received her PhD from MIT and her BS/MS degree from Clark Atlanta Univ. Her research applies the biology of molecular chaperonins to nanomedicine strategies in disease prevention.

\section{Aisha Walcott, Massachusetts Institute of Technology}

Aisha Walcott is a PhD candidate in the Electrical Engineering and Computer Science (EECS) Department at MIT. She received her BS from Clark Atlanta University, and her SM from the MIT EECS. Her research lies in persistent autonomy for mobile robots. 


\title{
THE ACADEMY OF COURAGEOUS MINORITY ENGINEERS: A MODEL FOR SUPPORTING MINORITY GRADUATE STUDENTS IN THE COMPLETION OF SCIENCE AND ENGINEERING DEGREES
}

\begin{abstract}
A major obstacle for minority students completing graduate degrees in science and engineering is a lack of support system. The purpose of this paper is to introduce the Academy of Courageous Minority Engineers (ACME) - a group designed to retain and enhance the experience of minority graduate students by facilitating and supporting programming geared toward completion of graduate degrees in multiple disciplines including electrical engineering, computer science, media arts and sciences, biology, and urban studies. While support or accountability groups are not a new idea, ACME strives to make this process systematic and focused through a web-based system, ACME Online that allows members to post and track their personal goals and comment on the goals of other members. Weekly forums are held to discuss and provide constructive feedback on the content of and progress toward research goals as well as discussion topics related to graduate school success including time management, preparing for qualifying exams, and advisor-advisee relationships. In another component of ACME, monthly lunch series are held to provide a diverse and supportive environment for graduate students to present research ideas, problems, papers, or results, and receive feedback from their peers in a range of disciplines. This paper will describe the technological infrastructure, management, and responsibilities of the members of ACME as well as information directly related to student success.
\end{abstract}

\section{Introduction}

The Department of Education Statistics suggests that while African-American enrollment rates in higher education continue to increase, graduation rates are comparatively low ${ }^{4}$. The quality of experience during the graduate process needs to be investigated. The National Opinion Research Center at the University of Chicago ${ }^{1}$ reports a $10 \%$ decrease in the number of black American doctorates in 2005. Black Ph.D. recipients had an average age of 36.7 (vs. 33.8 for all Americans), while taking an average of 12.7 years (vs. 10.4 years for white Americans). Furthermore, $16.2 \%$ of black American Ph.D. recipients planned postdoctoral study (vs. 22.7\% of all white American Ph.D. recipients).

Programs are being established to enhance the quality of the graduate process for minority graduate students. The effects of small informal groups with underlying commonality have been documented to produce excellent results ${ }^{5}$. This is due in large part to common denominators of respect for one another's opinions, genuine desire for members' success, and anxiety free environments for perceived failures.

Through focus groups of minority graduate students, McAfee, et al. (2006) discovered that personal and political aspects were major determining factors that led to the success of a graduate student ${ }^{3}$. This comes in contrast to undergraduate success where academics are deemed to be the major determining factor that led to successful graduation. The ACME model of peer 
support and academic goal attainment, established in 2003, supports a common-interest group for the express purpose of enhancing existing intellectual merits of its members by providing a professional environment with increased emotional support.

\section{$\underline{\text { Background }}$}

\section{Science and Engineering Graduate Minorities in a Majority Environment}

Elements of majority climate of the university that have traditionally hindered the persistence of minority doctoral students fall within three representative areas: 1) social dynamics, 2) physical resources, and 3) epistemological assumptions. Social dynamics include the openness of majority students, faculty, and administrators toward the minority student. Physical resources include assigned work space, research monies and equipment, and conference support. Epistemological assumptions include preconceptions by faculty and other students about the value and validity of the minority students' ability to contribute to the goals of the academy. Additionally, access to quality mentoring from relevant faculty may also be compromised. Within each of these areas, the majority environment may contain elements that communicate the message that minority presence is not valued or welcomed.

A major challenge to science and engineering Ph.D. programs is the recruitment and retention of minority doctoral students ${ }^{7}$. For example, in the Woodrow Wilson study entitled, "Diversity and the Ph.D.," recommendations were provided for improving the minority doctoral experience.

These recommendations include: 1) communication, 2) mentoring and professional experiences, 3) connecting race and need, and 4) research. Communication and research both include sharing best practices of successful programs and support models. Examples include being more responsive and improving the image of programs so they are attractive to minority graduate candidates. Mentoring and professional experiences provide opportunity and guidance for students around presenting their research, working with advisors, and negotiating the political side of graduate school. Connecting race and need charges university academic and administrative departments to consider minority status as well as need when allocating financial aid, admissions, and program resources. Many of these principles are evidenced in the work of the ACME model in supporting minority doctoral student success.

\section{Promoting Minority Success in Science and Engineering Ph.D. Programs}

There are a number of approaches to improve academic outcomes for all students, regardless of race. In The Responsive Ph.D. Initiative, another Woodrow Wilson Foundation initiative, the researchers assert that real change requires universities to embrace four guiding principles:

- A graduate school for real: A Ph.D. program with strong schools and graduate deans with real budgets and scope

- A cosmopolitan doctorate: A doctorate program that is rooted in academia, yet open and relevant to the real world

- An assessed excellence: A program willing to evaluate the quality of its academic offering in a meaningful way (e.g., with rewards and consequences)

- Drawn from the breadth of the populace: A program committed to reflecting the cultural diversity of the general public

For the reasons outlined in the previous section, the final objective is perhaps the most 
challenging of the four. Given the issues faced by minorities in a majority academic environment, institutions and researchers alike are interested in increasing the numbers of minorities that successfully finish. As noted in the introduction, minorities tend to take longer to obtain their degrees and are less likely to finish their degree at all. Accordingly, institutions and academics alike are interested in retention strategies -- support structures and resources to enhance and improve the minority graduate experience.

There are many different types of retention strategies for minorities, with some more effective than others. A study of undergraduate engineering programs Hermond (1995) identifies seven such strategies, each of which is analogous to graduate programs ${ }^{2}$. In summary, the identified strategies were:

1) Matriculation programs

2) Orientation programs

3) Academic Advising

4) Student Organizations/Affinity Groups

5) Tutoring/Academic Workshops

6) Non-Academic Advising/Personal Counseling

7) Financial Aid

The effectiveness of a strategy is arguably linked to the quality of its implementation. When students in the study were asked to report on the overall quality of the different programs at their university, the student-run affinity group was given the highest average rating, followed by financial aid and matriculation programs. The findings provide some evidence that peer groups play a central role in promoting a positive student experience, a key component of retention.

\section{Methodology}

The following section provides specific details related to the Academy of Courageous Minority Engineers.

\section{Participants}

Over the period of three years there have been 20-25 minority graduate student participants using the system with an average of 4-7 participants per session. Participants, ranging in age from 21 to 48, represent the range of disciplines at Massachusetts Institute of Technology including Electrical Engineering and Computer Science, Mechanical Engineering, Ocean Engineering, Health Sciences and Technology, Biology, Operations Research, Brain and Cognitive Sciences, and Media Arts and Sciences.

\section{ACME Format}

The ACME model is operationalized by implementing a series of goal-directed meetings, some of which are supported by the ACME online system. Accountability meetings are held each Thursday and last between one and one and a half hours. These meetings involve ACME members reporting on their goal status, accomplishments, challenges, and obstacles to goal completion. The group then directs their collective expertise and experience toward resolving any issues and planning of future goals. ACME members may not attend every ACME meeting, 
however, there must be four members to constitute a quorum. A rotating leadership system is used, based on the members' ACME system login identifications. In this system the leader for the week takes charge of conducting the various meeting activities, including coverage and monitoring of outstanding and accomplished goals of each participant. Special ACME sessions are dedicated to more formal research presentations, in addition to reviewing participants' goal status. The ACME lunch series, which occurs monthly, offers a supportive venue for members to present research ideas, problems, papers, or experimental results, and to garner feedback.

Attendance at these lunches ranges from 15-20 participants.

\section{Description of the Technology}

ACME is a web-based system designed to allow 24/7 access to all group members. Utilizing a standard web browser, users enter a login and password on the main page. The system has a database that logs all user actions and presents the last 10 user logins. On the main system page, users are presented with a tabbed navigation.

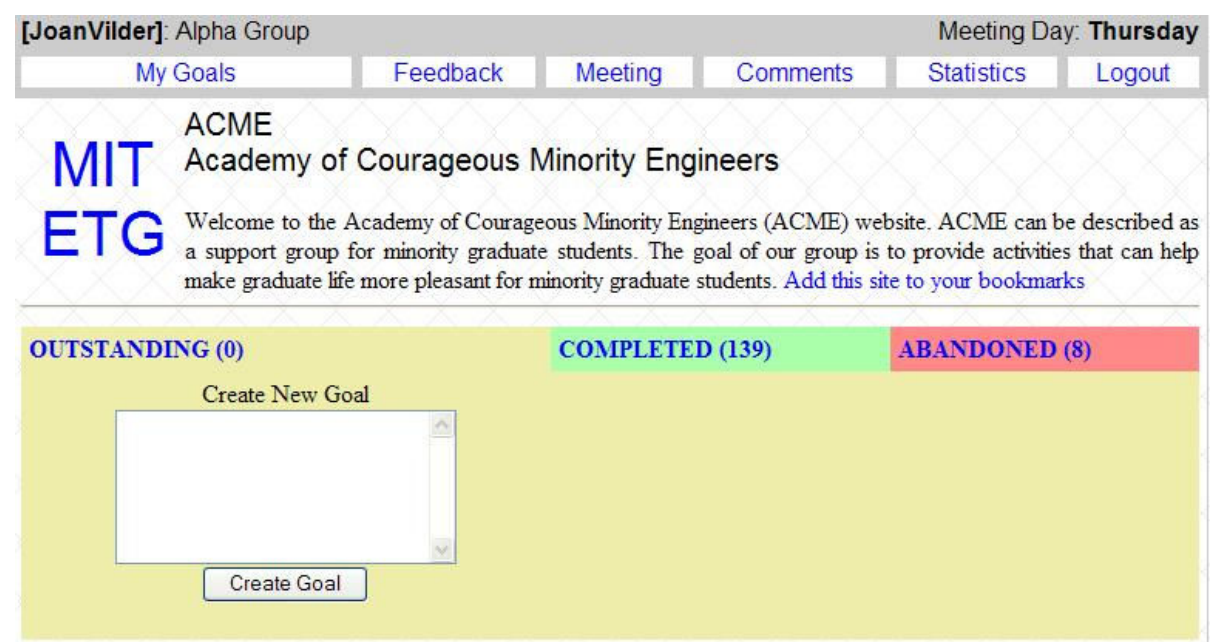

Figure 1. ACME main system page

From the main page, users can view their Outstanding, Completed and Abandoned Goals in the My Goals tab. Users enter a text description of their goal, and for each week that the goal remains uncompleted, a blinking dot is attached to that goal to motivate the user to complete it. In the Feedback tab, users can view the goals of other members in their ACME group. The Meeting tab allows users to indicate their attendance status for the next upcoming meeting. This feature allows users to coordinate ordering food and meeting location. The Comments tab allows users to view encouraging text-based messages from other users. The Statistics tab allows users to view general system statistics such as total logins and completed goals for all users. These statistics serve as a motivation for users to be competitive in their goal setting and achievement. Finally, a Logout tab allows the user to exit the system.

In addition to the web-based system, ACME Online has a daily email function. In order to remind users about their goals, meetings and progress of other members, the system has a daily script that analyzes the database for significant events (see figure 2 for a portion of the daily email). If the system determines there are no significant events, no email is sent. This feature allows users to quickly visualize recent activity on the ACME server without logging in. 


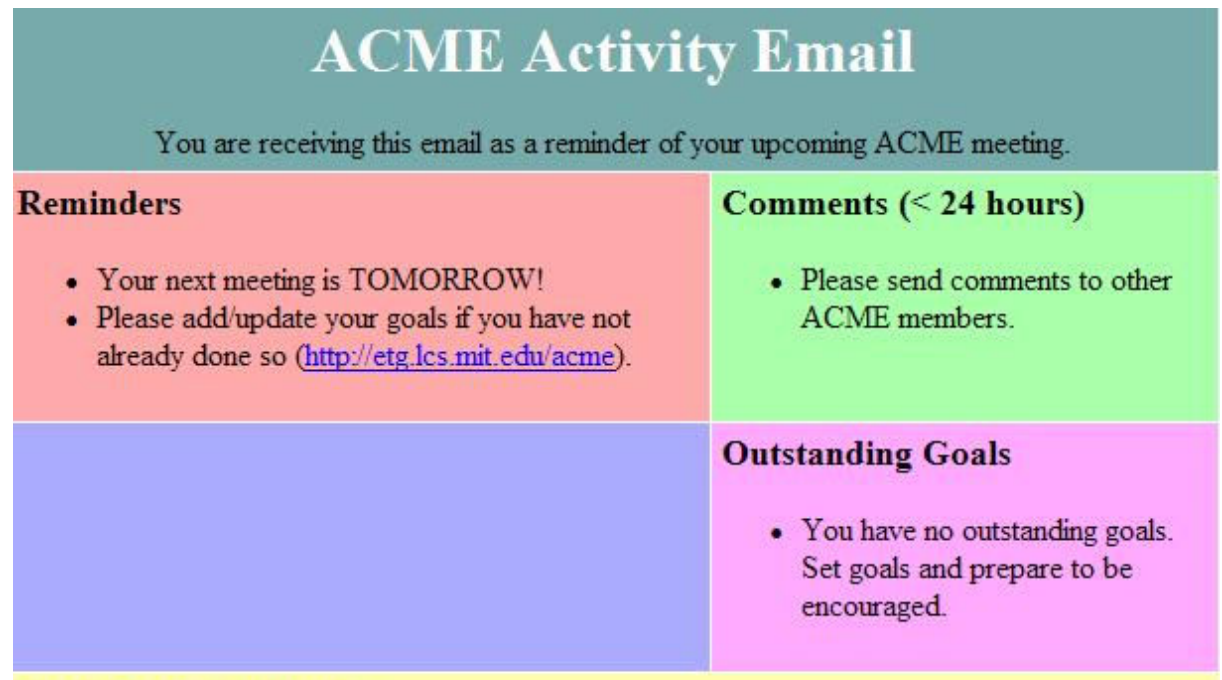

\section{Next Meeting Attendees}

Figure 2. Portions of the daily email sent to ACME members

The presentation layer of the website is hosted via an Apache web server. The HTML is dynamically generated via PHP 4 scripts and uses a MySQL database for storage. The system is hosted on a $2 \mathrm{GHz}$ Dell Linux Workstation with 1GB RAM and $80 \mathrm{~GB}$ hard drive. The workstation is connected to a $100 \mathrm{Mb}$ switch on MIT's local area network. Since most ACME groups tend to be small, the workstation is capable of hosting several ACME communities. The ACME system architecture is presented below.

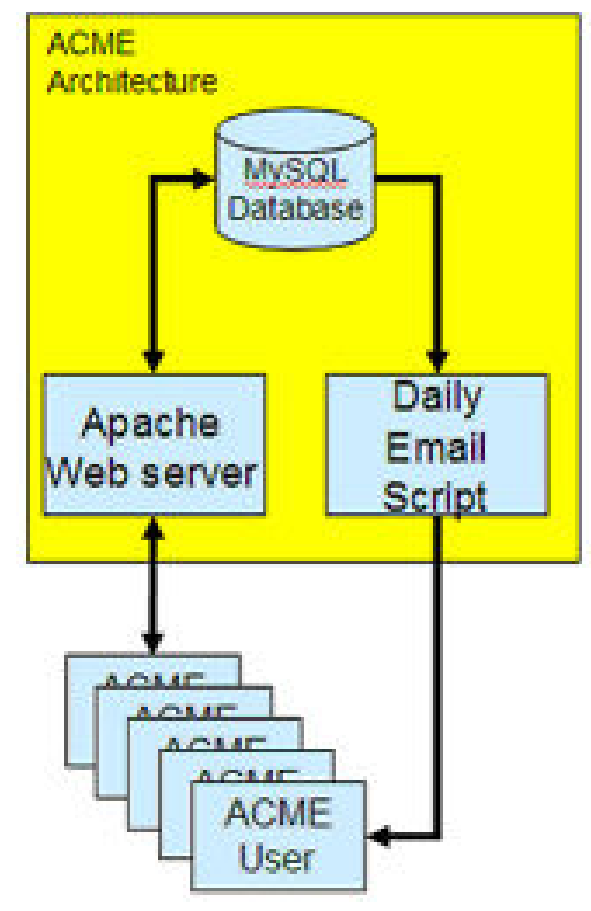

Figure 3. ACME system Architecture 


\section{Data sources}

Data presented represents information from January 17, 2004 to January 17, 2007. Quantitative data was obtained from ACME system log data. Each member's progress was tracked anonymously. Data points gleaned from the system logs include:

1. Attendance: The number of times a member attends ACME weekly meetings.

2. Access: The number of times each member logs into the ACME system.

3. Outstanding Goals: The number of individual goals set.

4. Completed Goals: The number of goals completed.

5. Overdue Goals: The number of goals that have yet to be completed in a 7-week period.

6. Abandoned Goals: The number of goals abandoned.

7. Comments: The number of comments received from other ACME members.

8. Total Goals: The total number of goals set.

Qualitative data was also gathered during meetings, including meeting attendance. Collected quantitative and qualitative data were organized into a number of time frames for comparative study. Those included:

- . N-year(s) Cumulative Data

- 90-days Cumulative Data

- 30-days Cumulative Data

- 7-days Cumulative Data

- Current Data

Data trend analysis was utilized to measure the effectiveness and use of the ACME system. Analyses performed included:

1. Analyze the effectiveness of an online reference group with a comparative study on Comments and Completed Goals.

2. Analyze the effectiveness of a traditional reference group with a comparative study on Attendance and Completed Goals.

3. Analyze ACME's usefulness and user adaptability with a comparative study on Access and Total Goals.

4. Analyze user effective time management with a comparative study on Outstanding Goals, Completed Goals and Overdue Goals.

5. Analyze user willingness to adapt to change with a comparative study on Outstanding Goals and Abandoned Goals.

The next section discusses the analysis and interpretation of this quantitative and qualitative data.

\section{$\underline{\text { Results and Discussion }}$}

A variety of analyses were performed on the study data. A portion of the results are presented below followed by a brief discussion of their implications for the ACME model and ACME Online system. 


\section{Results}

Optimum Group Size to be Effective: Logins vs. Time Period

As a matter of course, ACME allowed for a flexible group size. Over a 3-year time frame the average number of active participants was between 4-7 individuals. This active group size is in line with optimal group sizes for intellectual based social groups whose express purpose is to leverage the collective knowledge for each member's benefit. Such group sizes are indicative of members forming deep bonds and close interactions in an informal setting. Also, such group sizes better allowed members to effectively address each other's issues during the weekly onehour face-to-face meeting sessions.

\section{Group Efficacy: Completed Goals vs. Time Period}

From the optimal group size of 4-7 individuals, initial data analysis showed two members actively reviewing and completing goals on a daily basis. The remaining members of the optimal group demonstrated a less frequent review and completion of goals. Data suggests these members completing goals on a weekly basis. The members who reviewed their goals on a daily bases were observed to be star performers with the greatest number of goals completed over their ACME membership lifetime. Over the 3-year period of analysis, the constituency changed with new members replacing old members as they graduated while still sustaining the optimal group size of 4-7 individuals. Except for the star performers, the group members tended to have similar goal behaviors, completing the same number of total goals over the lifetime of their membership at the similar rates. There was no correlation with the continual activity of an ACME member to the total number of goals completed over that member's lifetime.

\section{Face to Face Motivation vs. Online Motivation: Number of Comments vs. Time Period}

It was noted that online commentary and suggestions experienced a precipitous drop over the 3year period. Much of the member support came from the weekly meetings. This follows the trend seen in computer-mediated-communication when compared to face-to-face communication in small groups ${ }^{6}$. In the long term, however, computer-mediated-communication had few effects on information sharing or performance. While such communication established and validated ACME group membership, member "presence" was more accurately evidenced in the levels of face-to-face participation. Also, computer-mediated-communications showed potential for preventing productivity loss, especially with the likelihood of performance evaluation during future FTF interactions with their online group members ${ }^{5}$. This increased productivity in research work was also evidenced within the ACME group. Members were aware that their posted completion goals were published to the larger ACME membership. This provided added incentive to push toward accomplishing work goals before scheduled face-to-face meetings.

\section{Discussion}

The ACME group reached a steady-state regarding number of members at various times over the three year period. As new members joined and graduated out of the group, new steady-states 
were achieved in regards to levels of participation and goal completion. In particular, important success indicated for ACME members was their level of participation, particularly in the face-toface aspects outlined in the model. Face-to-face interactions resulted in formation of the strongest social and intellectual ties, and served as the glue that sustained group longevity and effectiveness. Additionally, the public sharing of individual completion goals added the element of accountability that encouraged more regular individual progress toward goal completion.

Further development of the ACME online system to increase its usability and promote easier connections between members should be explored. One area to be addressed is the number of software features offered. Many ACME Online users have expressed a desire for more options when creating goals. However, the system does not provide a mechanism to explicitly distinguish long-term from short-term goals or allow a goal to be sub-divided into sub-goals. The only means of changing goal granularity is by modifying a goal's associated text descriptions. Finally, future revisions of the ACME online system could provide the capability to specify target completion dates for goals and to divide long-term goals into components.

More effective implementation of the "accountability" aspect of the ACME model over an extended period of time should be explored. As presented earlier in this section, the goal completion rate tends to decrease over time. Although creating a positive, supportive atmosphere for members is a key aspect of ACME, it is also important to provide sustained motivation to members so they are more likely to complete their doctoral programs in a more timely fashion.

An important issue to consider is the sustainability of the ACME model as founding members graduate out of MIT. Currently, most active ACME participants have been group members since the program's inception. Although incoming graduate students have joined the group, over time, these newer members have been generally less consistent in their meeting attendance, often dropping out of the group altogether. Further investigating of best practices for engaging new members to become more vested in the ACME model is critical to the program's long-term viability.

\section{Conclusion}

The ACME model has provided a mechanism for connecting minority graduate students and addressing their particular needs for success within the majority institution. ACME serves its membership along several dimensions, including provided peer mentorship, professional and leadership training, accountability for positive doctoral program progress, and strengthening the associations among minority graduate students from various disciplines. Although the ACME model and this paper address issues specific to minority graduate students, the work has broader applications across the entire graduate student body. Just as the ACME model contributes to identifying and addressing minority graduate student needs, the model could be utilized also to address those issues relevant to all graduate students. The value of the ACME model to the majority institute as a whole is it helps users better understand those issues specific to the minority graduate student in a majority environment. A strength of the ACME experience is the teasing out of those systemic obstacles that cut across different departments, which suggests they are institutional in nature. Such knowledge could shine a spotlight on the work the majority institute should engage itself in to better serve all graduate students. 


\section{Bibliography}

1. Chicago, T. N. O. R. C. a. t. U. o. Retrieved from http://www.norc.org/ On November 15, 2006.

2. Hermond, D. (1995) Measuring the Retention Strategies of a Minority Engineering Program: A Service Quality Perspective. Journal of Engineering Education

3. McAfee, L.C., Ferguson, D.L. (2006) Status and Experiences of Minority Graduate Students, Postdoctoral Fellows, and Faculty in Science, Technology, Engineering, and Mathematics Disciplines." American Society for Engineering Education Annual Conference in Chicago, IL (June 19, 2006, ASEE Paper 2006-2177).

4. National Center for Education Statistics. Projections of Education Statistics to 2015 (NCES 2006-084). U.S. Department of Education. Washington, DC: National Center for Education Statistics. Retrieved from http://nces.ed.gov/pubs2006/2006084.pdf on November 1, 2006.

5. Olaniran, B. (1994) "Group Performance in Computer-Mediated and Face-to-Face Communication Media." Management Communication Quarterly, Vol. 7, No. 3, 256-281.

6. Straus, S. (1996) "Getting a Clue: The Effects of Communication Media and Information Distribution on Participation and Performance in Computer-Mediated and Face-to-Face Groups." Small Group Research, Vol. 27, No. 1, 115-142.

7. Woodrow Wilson Foundation, The Responsive Ph.D.: Innovations in U.S. Doctoral Education. Retrieved from http://www.woodrow.org/newsroom/News_Releases/ResponsivePhD_overview.pdf on March 8, 2006. 